\title{
A NOTE ON THE FORMATION OF STELLAR ABSORPTION LINES
}

\author{
P. SWINGS AND OTTO STRUVE
}

\section{ABSTRACT}

Microphotometer measures of the total absorptions of lines of $O$ II within the wing of $\mathrm{H \gamma}$, and of $\mathrm{CaH}$ within the wing of $\mathrm{H \epsilon}$, show departures from the normal absorptions predicted from the multiplet intensities of these lines. The departures increase with the wing absorption, but the effect is more pronounced for $O$ II than for $\mathrm{CaH}$. Eddington's theory of absorption lines leads to a theoretical evaluation of the effect. The remaining discrepancies between this theory and actual observation are unexplained.

I. In a paper by Unsöld, Struve, and Elvey ${ }^{\mathrm{I}}$ attention was called to the fact that the total absorptions of stellar lines superposed over the wings of broad hydrogen lines are appreciably reduced by the effect of the hydrogen absorption, which prevents us from seeing as deep into the star's atmosphere as we would if there were no hydrogen wings. As a consequence, the ratio $K / H$ in a Lyrae was found to be I.92 in place of the usual value of $\sqrt{2}=\mathrm{I} .4 \mathrm{I}$. A similar effect is also observed for the $O$ II lines $\lambda \lambda 4346,4347,4349$, and 435 I, which fall upon the wing of $\mathrm{H \gamma}$ in the early B-type stars. The departures of the total intensities from their normal values depend upon the amount of hydrogen absorption. The latter produces, in a sense, an additional amount of general opacity in the star's atmosphere, and it seems worth while to compare the measured line absorptions with those given by the theory.

2. The observational material consists of single-prism spectrograms, made on the fine-grain "Eastman Process" emulsion, of the following stars: $\kappa$ Orionis, Bo (I plate); $\zeta$ Persei, BI (2 plates); $\tau$ Scorpii, Bo (3 plates); $\theta$ Ophiuchi, B2 (I plate); a Cygni, A2 (I plate); $\eta$ Leonis, Ao (3 plates); a Lyrae, Ao (2 plates); a Canis Majoris, Ao (I plate). The results of the measurements are given in Tables I and II. In Table III the total absorptions of the $O$ II lines are reduced to an arbitrary value of I0.0 for $\lambda$ 43 I 7 . Figure I shows an average curve of growth for those $O$ II lines which are not affected by hydrogen wings. The precision of the measures is not

I $Z$ s.f. Ap., I, 324, I930. 
TABLE I

B-TYPE STARS

\begin{tabular}{|c|c|c|c|c|c|c|c|c|c|c|}
\hline \multirow{2}{*}{$\begin{array}{l}\text { MULTI- } \\
\text { PLET }\end{array}$} & \multirow{2}{*}{ LiNe } & \multirow{2}{*}{$\begin{array}{l}\text { THEOR. } \\
\text { INT. }\end{array}$} & \multicolumn{2}{|c|}{$\kappa$ ORIONIS } & \multicolumn{2}{|c|}{$\zeta$ Persei } & \multicolumn{2}{|c|}{$\tau$ SCORPII } & \multicolumn{2}{|c|}{$\theta$ OPHIUCHI } \\
\hline & & & Abs. & H-Wing & Abs. & H-Wing & Abs. & H-Wing & Abs. & $\mathrm{H}$-Wing \\
\hline \multirow{7}{*}{$\begin{array}{l}\text { Orry }{ }^{4} \mathrm{P}- \\
\mathrm{e}^{4} \mathrm{P}^{0} \ldots\end{array}$} & & & A & $\begin{array}{l}\text { per } \\
\text { cent }\end{array}$ & A & $\begin{array}{l}\text { per } \\
\text { cent }\end{array}$ & A & $\begin{array}{l}\text { per } \\
\text { cent }\end{array}$ & A & $\begin{array}{l}\text { per } \\
\text { cent }\end{array}$ \\
\hline & $(4317.16)$ & $39 \cdot 7$ & 0.05 & 0 & O. I 4 & 0 & 0.07 & o & 0.05 & 0 \\
\hline & I9.65 & $4^{2} \cdot 9$ & .06 & 0 & . I 3 & 0 & .08 & 0 & .05 & $\circ$ \\
\hline & $25 \cdot 77$ & 7.9 &. $\mathrm{OI}$ & 0 & .05 & 0 & .04 & 0 & .02 & $\circ$ \\
\hline & $45 \cdot 57$ & $39 \cdot 7$ & .07 & 0 & .09 & 7 & .05 & I 2 & $.0 \mathrm{r}$ & I 7 \\
\hline & $49 \cdot 43$ & $100 . c$ &. $\mathrm{I} 2$ & 0 & .26 & 3 & .09 & 5 & .03 & Io \\
\hline & $66.9 \mathrm{I}$ & $4^{2} \cdot 9$ & .06 & 0 & .14 & 0 & .08 & o & .05 & $\circ$ \\
\hline \multirow{2}{*}{$\begin{array}{l}O \operatorname{Iry}^{2} \mathrm{D}- \\
\mathrm{f}^{2} \mathrm{D}^{\circ} \ldots\end{array}$} & 47.43 & $64 \cdot 3$ & .05 & 0 & .06 & 4 & .03 & 6 & . OI & I 2 \\
\hline & $5^{\text {I. }} 27$ & 100.0 & 0.06 & 0 & 0.10 & 2 & 0.06 & 3 & 0.02 & 7 \\
\hline
\end{tabular}

TABLE II

A-TYPE STARS

\begin{tabular}{|c|c|c|c|c|c|c|c|c|c|c|}
\hline \multirow{2}{*}{ LINE } & \multirow{2}{*}{$\begin{array}{l}\text { Theor } \\
\text { Int. }\end{array}$} & \multirow{2}{*}{$\sqrt{\text { Tн. INT }}$} & \multicolumn{2}{|c|}{$a$ CYGNI } & \multicolumn{2}{|c|}{$\eta$ LEONIS } & \multicolumn{2}{|c|}{ a LYRAE } & \multicolumn{2}{|c|}{$a$ CAN. MAJ. } \\
\hline & & & Abs. & $\mathrm{H}$-W Wing & Abs. & H-Wing & Abs. & $\mathrm{H}$-Wing & Abs. & H-Wing \\
\hline $\begin{array}{l}\mathrm{H} \ldots \ldots \\
\mathrm{K} \ldots \ldots \\
\text { Ratio } \\
\mathrm{K} / \mathrm{H} .\end{array}$ & $\begin{array}{l}\text { I } \\
2\end{array}$ & $\begin{array}{l}\text { I. } \\
\text { I. 4I } \\
\text { I. 4I }\end{array}$ & $\begin{array}{c}\text { A } \\
\text { O. } 7 \text { I } \\
\text { I.02 } \\
\text { I . } 44\end{array}$ & $\begin{array}{c}\text { per } \\
\text { cent } \\
25 \\
0\end{array}$ & $\begin{array}{c}\text { A } \\
0.25 \\
0.43 \\
\text { I. } 72\end{array}$ & $\begin{array}{c}\text { per } \\
\text { cent } \\
43 \\
0\end{array}$ & $\begin{array}{c}\text { A } \\
0.26 \\
0.56 \\
2.15\end{array}$ & $\begin{array}{c}\text { per } \\
\text { cent } \\
74 \\
0\end{array}$ & $\begin{array}{c}\text { A } \\
0.22 \\
0.58 \\
.2 .64\end{array}$ & $\begin{array}{c}\text { per } \\
\text { cent } \\
62 \\
0\end{array}$ \\
\hline
\end{tabular}

TABLE III

\begin{tabular}{|c|c|c|c|c|c|c|c|c|}
\hline \multirow{3}{*}{ LINE } & \multirow{3}{*}{$\sqrt{\text { TH. INT. }}$} & \multirow{2}{*}{$\begin{array}{c}\text { OUtSIDE OF Wing } \\
\text { (MEAN Obs. INT. RE- } \\
\text { DUCED to } \lambda_{43} \text { I } 7=\text { IO) }\end{array}$} & \multicolumn{6}{|c|}{ INSWE OF WING } \\
\hline & & & \multicolumn{2}{|c|}{$\zeta$ Persei } & \multicolumn{2}{|c|}{$\tau$ Scorpii } & \multicolumn{2}{|c|}{$\theta$ Ophiuchi } \\
\hline & & & $O_{\text {II }}$ & $H$ & $O \mathrm{II}$ & $H$ & $O$ II & $H$ \\
\hline $43 \times 7 \ldots$ & 6.3 & IO. 0 & $\ldots \ldots$ & $\ldots \ldots$ & $\ldots \ldots$ & $\ldots \ldots$ & $\ldots \ldots$ & $\ldots \ldots$ \\
\hline $20 \ldots$ & 6.5 & IO. 5 & $\ldots \ldots$ & $\ldots \ldots$ & $\ldots \ldots$ & $\ldots \ldots$ & $\ldots \ldots$ & $\ldots \ldots$ \\
\hline $26 \ldots$ & 2.8 & 4.0 & $\ldots \ldots$ & $\ldots \ldots$ & $\ldots \ldots$ & $\ldots \ldots$ & $\ldots \ldots$ & $\ldots \ldots$ \\
\hline $67 \ldots$ & 6.5 & 10. 8 & $\ldots \ldots$ & $\ldots \ldots$ & $\ldots \ldots$ & $\ldots \ldots$ & $\ldots \ldots$ & $\ldots$ \\
\hline $46 \ldots$ & 6.3 & 7.0 & 6 & 7 & 7 & I 2 & 2 & I7 \\
\hline $49 \ldots$ & IO. 0 & 25.0 & $\ldots \ldots$ & $\ldots \ldots$ & 9 & 5 & 6 & IO \\
\hline
\end{tabular}


sufficient to construct separate curves of growth for each star. The total absorptions of lines affected by hydrogen wings are shown by crosses. They were, of course, measured from the wing of the hydrogen lines and not from the continuous spectrum.

Figure 2 shows the results of $\mathrm{H}$ and $\mathrm{K}$ for $C a \mathrm{II}$. Here the material is insufficient for the construction of a curve of growth. Consequently, we adopt the relation $A \propto \sqrt{\text { Th. Int. }}$

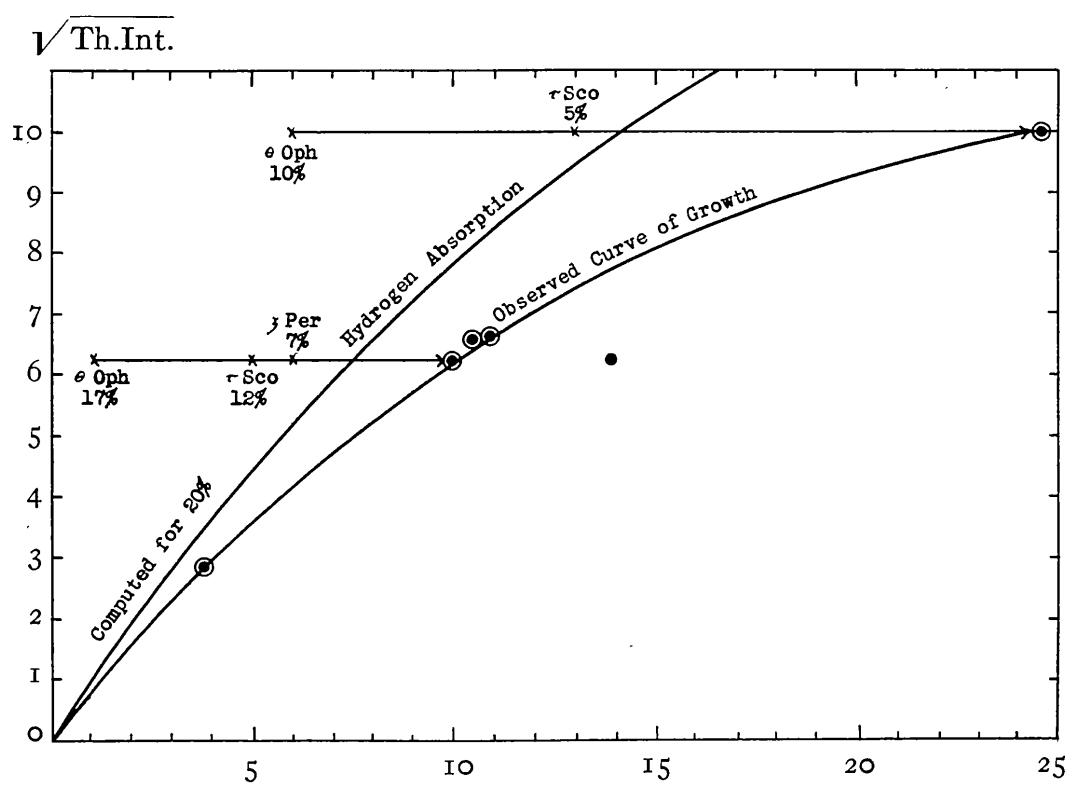

FIG. I. - Observed absorptions of $O$ II lines (reduced to $\lambda 4_{43}$ I $7=$ ro). $\odot$ Outside of wing; $X$ inside of wing.

In both diagrams the systematic departures of the lines affected by wing absorption are clearly seen. The percentages of wing absorption are indicated in the figures and show a fairly marked increase of departure with increase of wing absorption.

3. Eddington ${ }^{2}$ has given the following expression for the absorption within a line:

$$
A=\mathrm{I}-\frac{\mathrm{I}+\frac{2}{3} q}{\mathrm{I}+\eta+\frac{2}{3} q}
$$

where $q^{2}=3(\mathrm{I}+\eta)(\mathrm{I}+\epsilon \eta)$ and $\eta=l / k$ is the ratio of the absorption coefficient in the line to the coefficient of continuous absorption,

2M.N., 89, 620, 1929. 
while $\epsilon$ is the fraction of the absorbed radiation that is lost by superelastic collisions.

We shall assume that $\epsilon=0$; and we shall, furthermore, distinguish between the coefficients of line absorption $l_{0}$, for the oxygen

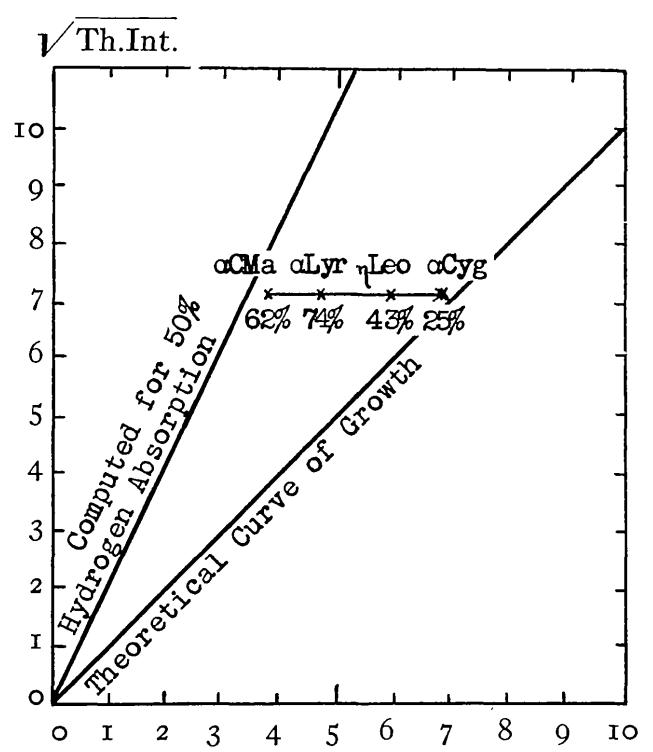

FIG. 2.- Observed absorptions of $C a \mathrm{II}$ (reduced to $K=\mathrm{ro}$ )

lines, and $l_{H}$, for $H \gamma$. Then, assuming that the hydrogen wing absorption is similar to general absorption within the star's atmosphere, and that there is no stratification, we have

$$
A=\mathrm{I}-\frac{\mathrm{I}+\mathrm{I} \cdot \mathrm{I} 6 \sqrt{\mathrm{I}+\frac{l_{0}}{k+l_{H}}}}{\mathrm{I}+\frac{l_{0}}{k+l_{H}}+\mathrm{I} \cdot \mathrm{I} 6 \sqrt{\mathrm{I}+\frac{l_{0}}{k+l_{H}}}} .
$$

The coefficient of line absorption for $O$ II may be written

$$
l_{0}=a_{m} f\left(\lambda-\lambda_{0}\right),
$$

where $a_{m}$ is a coefficient numerically equal to the theoretical multiplet intensity of the line in question. Equation (I) contains the term $l_{0} /\left(k+l_{H}\right)$. This may be written:

$$
\frac{l_{0}}{k+l_{H}}=\left(\frac{a_{m} f}{\mathrm{I}+l_{H} / k}\right) \frac{l_{0}}{k}
$$


Accordingly, the same absorption $A$ will be observed for a line in the wing as for another line outside the wing, provided that

$$
a_{m}^{\prime}=\frac{a_{m}}{\mathrm{I}+l_{H} / k} .
$$

From Eddington's paper ${ }^{3}$ we find that for an intensity of 0.8 within the hydrogen wing the corresponding value of $\eta=l_{H} / k=0.62$. Accordingly, $a_{m^{\prime}}=0.62 a_{m}$. With this value of $a_{m}$ we have computed the theoretical curve of growth that would correspond to a wing absorption of 20 per cent. The observed points in Figure I seem to indicate that the real departures are larger than those computed.

For the $\mathrm{H}$ line of $C a$ II a similar computation has been made, assuming that the wing absorption of $\mathrm{H \epsilon}$ near the line $\mathrm{CaH}$ is 50 per cent. Eddington's data give for $A=0.5, \eta=3.43$, and consequently $a_{m^{\prime}}=0.26 a_{m}$. Figure 2 shows that the observed points have smaller departures than would be expected from the theory.

4. Similar results are obtained if, instead of assuming that the hydrogen wing absorption is similar to general absorption, we suppose that the absorption in the wing is formed by pure scattering. Let us consider first the case of an $O$ II line appearing in the wing of $H \gamma$. The flux inside of the $O$ II line is

$$
F\left(\frac{l_{0}+l_{H}}{k}\right)=\frac{\mathrm{I}+\mathrm{I} \cdot \mathrm{I} 6 \sqrt{\mathrm{I}+\frac{l_{0}+l_{H}}{k}}}{\mathrm{I}+\frac{l_{0}+l_{H}}{k}+\mathrm{I} . \mathrm{I} 6 \sqrt{\mathrm{I}+\frac{l_{0}+l_{H}}{k}}}:
$$

the flux outside of the $O$ II line is

$$
F\left(\frac{l_{H}}{k}\right)=\frac{\mathrm{I}+\mathrm{I} \cdot \mathrm{I} 6 \sqrt{\mathrm{I}+\frac{l_{H}}{k}}}{\mathrm{I}+\frac{l_{H}}{k}+\mathrm{I} \cdot \mathrm{I} 6 \sqrt{\mathrm{I}+\frac{l_{H}}{k}}} .
$$

3 Loc. cit. 
Thus the absorption in an $O$ II line appearing in the wing of $H \gamma$ is

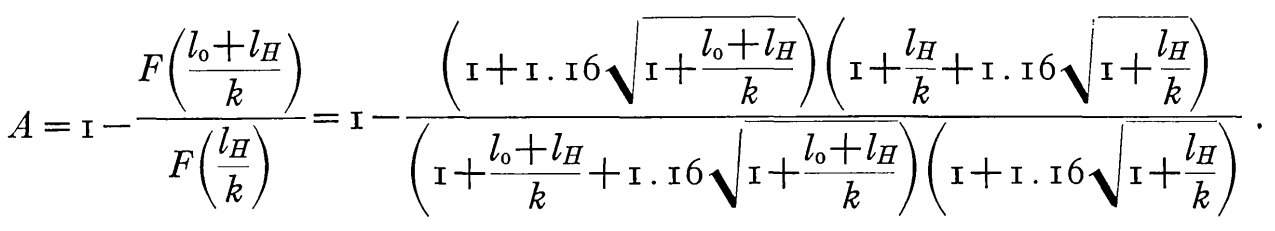

For $l_{H} / k$ we may use Eddington's table; for $l_{0} / k$ we use the same table, considering the percentage of absorption that the $O$ II line would have outside of the wing.

The results of the calculations for the two lines 4346 and 4349 are summarized in Table IV; the third column for each star gives the reduction factors for the intensities of the lines appearing in the wing. It is obvious that these factors are much smaller than the observed values.

TABLE IV

COMPUTED REDUCTIONS OF THE INTENSITIES OF THE $O$ II LINES

\begin{tabular}{|c|c|c|c|c|c|c|c|c|c|}
\hline \multirow[b]{2}{*}{ LiNE } & \multicolumn{3}{|c|}{$\zeta$ PERSEI } & \multicolumn{3}{|c|}{$\tau$ SCORPII } & \multicolumn{3}{|c|}{$\theta$ OPHIUCHI } \\
\hline & $l_{H} / k$ & $l_{0} / k$ & $\begin{array}{l}\text { Reduc- } \\
\text { tion } \\
\text { Factor }\end{array}$ & $l_{H} / k$ & $l_{0} / k$ & $\begin{array}{l}\text { Reduc- } \\
\text { tion } \\
\text { Factor }\end{array}$ & $l_{H} / k$ & $l_{0} / k$ & $\begin{array}{l}\text { Reduc- } \\
\text { tion } \\
\text { Factor }\end{array}$ \\
\hline $\begin{array}{r}4345 \cdot 57 \ldots \ldots \ldots \\
49.43 \ldots \ldots \ldots\end{array}$ & $\begin{array}{l}0.2 \\
0.08\end{array}$ & $\begin{array}{l}0.4 \\
0.66\end{array}$ & $\begin{array}{l}0.92 \\
0.95\end{array}$ & $\begin{array}{l}0.36 \\
0.15\end{array}$ & $\begin{array}{l}0.26 \\
0.42\end{array}$ & $\begin{array}{l}0.9 \\
0.93\end{array}$ & $\begin{array}{l}0.5 \\
0.3\end{array}$ & $\begin{array}{l}0.2 \\
0.35\end{array}$ & $\begin{array}{l}0.8 \mathrm{I} \\
0.86\end{array}$ \\
\hline
\end{tabular}

The opposite conclusion is reached for the $\mathrm{H}$ line of $C a \mathrm{II}$, as is shown in Table V. The computed ratios $\frac{\text { Intensity of } \mathrm{K}}{\text { Intensity of } \mathrm{H}}$ are increasing in the same direction as the observed values, but are much too large.

5. The opposite sense in which the two sets of observations depart from the theory is rather puzzling. Our assumptions for $l_{H}$ may be erroneous, but it does not seem likely that this is the cause of the discrepancy. One might be tempted to interpret the results as an effect of stratification. ${ }^{4}$ But it is quite improbable that in the B

${ }_{4}$ This effect of stratification must be carefully defined. In considering the scattering hypothesis, we assume that all the atoms are completely mixed; but the lines of $O$ 
stars the hydrogen wings are formed above the $O$ II lines while in the A stars they are formed below the $C a$ II lines. The observations are not very accurate and large systematic errors may, conceivably, have affected our results for $O$ II. Nevertheless, the departure from the normal intensities of $\lambda \lambda 4346,4349,4347,435 \mathrm{I}$ is apparent even from a visual inspection of the spectrograms, while the computed departures for wing absorptions of the order of ro per cent should hardly be noticeable. Under the circumstances it seems best to await more accurate observational data before an attempt is made to explain the phenomenon.

TABLE V

COMPUTED RATIOS OF THE INTENSITIES OF THE $\mathrm{K}$ AND H LINES OF $C a$ II

\begin{tabular}{|c|c|c|c|c|}
\hline Star & $\frac{l_{H \epsilon}}{k}$ & $\frac{l_{C a \Pi}}{k}$ & $\begin{array}{c}\text { Computed } \\
\text { Ratios } K / H\end{array}$ & $\begin{array}{c}\text { Observed } \\
\text { Ratios } K / H\end{array}$ \\
\hline 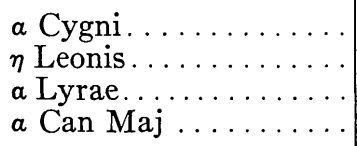 & $\begin{array}{l}0.85 \\
\text { I. } 6 \\
\text { I } \\
7 .\end{array}$ & $\begin{array}{l}3 \cdot 8 \\
\text { I.I } 5 \\
2 . \text { I } 5 \\
\text { I. } 45\end{array}$ & $\begin{array}{l}\text { I. } 82 \\
2.62 \\
5.8 \\
6 .\end{array}$ & $\begin{array}{l}\text { I. } 44 \\
\text { I. } 72 \\
2 . \mathrm{I} 5 \\
2.6 \mathrm{I}\end{array}$ \\
\hline
\end{tabular}

In conclusion, attention may be called to the fact that the stellar intensities of blended lines present a problem that is essentially similar to that discussed here. Evidently it is not permissible in radialvelocity work to take simply the weighted mean for the wave-length of the blend, using for the weights the laboratory intensities of the lines. Whenever the intensities of the components are not the same, the blended wave-length will depend upon the shapes of the two lines. For example, the wave-length of $H \epsilon$ should be much less affected by $\mathrm{Ca}$ II $H$ in Sirius than in $\eta$ Leonis.

We wish to express our thanks to Dr. Chandrasekhar for several valuable suggestions.

YERKES OBSERVATORY

November 24, I935

and $H$ (or of $C a$ II and $H$ ) originate in different levels; this appears clearly when the flux inside of a line is plotted as a function of the depth. On the other hand, we may have a real chemical stratification of the elements. It is this type of stratification that we are interested in. 
PLATE X

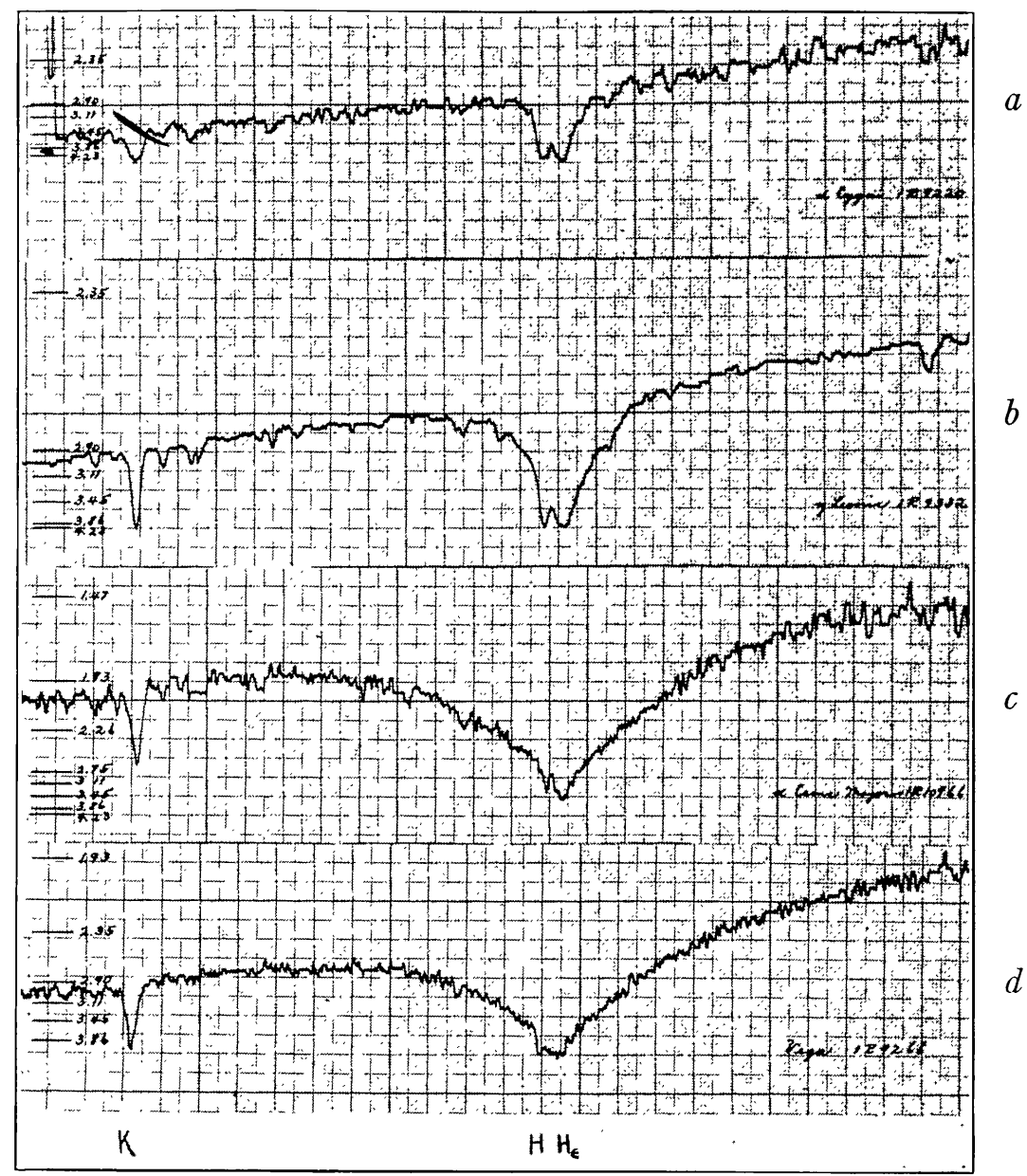

Microphotometer Tracings of Stellar Spectra: (a) a Cygni; (b) $\eta$ Leonis; (c) a Canis Majoris; $(d) a$ Lyrae 